\title{
Activation of the insulin-like growth factor binding protein-5 promoter by parathyroid hormone in osteosarcoma cells requires activation of an activated protein-2 element
}

\author{
Mary S Erclik and Jane Mitchell \\ Department of Pharmacology, University of Toronto, 1 King's College Circle, Room 4342, Toronto, Ontario M5S 1A8, Canada \\ (Requests for offprints should be addressed to J Mitchell; Email: jane.mitchell@ utoronto.ca)
}

\begin{abstract}
We have previously shown that parathyroid hormone (PTH) stimulates the expression of insulin-like growth factor binding protein-5 (IGFBP-5) transcript levels in the osteosarcoma cell-line, UMR106-01 cells. In the present study we examined the molecular basis for the PTH induction of IGFBP-5 mRNA in these cells. PTH had no effect on the half-life of the IGFBP-5 transcript but did stimulate the transactivation of the proximal 889 base pairs of the rat IGFBP $5^{\prime}$ flanking region in a luciferase fusion construct, suggesting that PTH stimulates transcript levels through transcriptional mechanisms. Progressive $5^{\prime}$ deletions to -59 base pairs of the proximal promoter region had no effect on PTH induction of transactivation, indicating that an element existed within the first -59 base pairs upstream of the transcription start site that was responsive to PTH. Within the -59 base pairs there are CCAAT/enhancer binding protein (C/EBP), E-box, nuclear factor-1 (NF-1) and activator protein-2 (AP-2) elements. Mutation of the C/EBP, E-box or NF-1 elements had no effect on the ability of PTH to induce the transactivation of the IGFBP-5 promoter. Mutation of the AP-2 element resulted in a $40 \%$ reduction of PTH-stimulated luciferase activity. When three tandem repeats of the AP-2 consensus sequence were fused to a luciferase reporter, PTH stimulated a $25 \%$ increase in reporter activity. Electrophoretic mobility shift assays using UMR106-01 cell nuclear extracts showed that PTH caused a prominent shifted band in a probe spanning the region containing all four elements. The shifted band was almost completely absent when the probe contained a mutated AP-2 element. These results suggest that the AP-2 element functions in the PTH induction of IGFBP-5 gene expression.
\end{abstract}

Journal of Molecular Endocrinology (2005) 34, 713-722

\section{Introduction}

Insulin-like growth factors I and II (IGF-I and IGF-II) are secreted by skeletal cells and represent a significant portion of the growth factors produced by bone cells (Canalis et al. 1988, Bautista et al. 1990). IGFs have mitogenic effects on osteoblasts and can also enhance the differentiated function of these cells (Zhao et al. 2000). The activity of IGFs is controlled, in part, by binding proteins (Rajaram et al. 1997, Firth \& Baxter 2002). Osteoblasts secrete six IGF binding proteins (IGFBPs) into the extracellular matrix where they either positively or negatively influence the binding of IGFs to their cognate receptors (McCarthy et al. 1994, Jones \& Clemmons 1995). IGFBP-5 is the major binding protein stored in bone displaying the unique ability to bind with high affinity to extracellular mineral hydroxyapatite (Campbell \& Andress 1997). In many studies, IGFBP5 has been shown to stimulate the proliferation and activity of osteoblasts in vitro and a recent study demonstrated that decreasing IGFBP- 5 by siRNA in U2 cells decreased osteoblast number, due to increased apoptosis (Andress \& Birnbaum 1992, Mohan et al.
1995, Miyakoshi et al. 2001, Yin et al. 2004). A stimulatory effect of IGFBP-5 was also seen in vivo with systemic administration of recombinant IGFBP-5 in mice (Richman et al. 1999, Andress 2001). Although its main mechanism of action is presumed to involve IGF-I there are also findings obtained through in vivo and in vitro studies to indicate that IGFBP-5 may stimulate osteoblast activity through IGF-independent mechanisms (Andress \& Birnbaum 1992, Miyakoshi et al. 2001). In contrast to these studies, Durant et al. (2004a) demonstrated that overexpression of IGFBP-5 in MC3T3 osteoblastic cells decreased their function in culture. Additionally, Devlin et al. (2002) have demonstrated that transgenic mice that overexpress osteoblastic IGFBP-5 display decreased numbers of osteoblasts and decreased osteoblast activity resulting in a transient decrease in bone volume. However, in a subsequent study in mice overexpressing IGFBP-5 N-terminal fragments in osteoblasts, no discernible phenotype was observed (Durant et al. 2004b). Together, these studies suggest that either too little or too much IGFBP-5 may be deleterious to osteoblast survival and function in bone and therefore it is important to understand the 
factors that control its transcription, synthesis and secretion.

Regulation of IGFBP-5 gene expression has been described in multiple cell types by several factors. In human fibroblasts cAMP can stimulate IGFBP-5 transcription through the binding of activator protein-2 (AP-2) transcription factor to its proximal recognition sequence immediately upstream of the IGFBP-5 TATA box (Duan \& Clemmons 1995). cAMP can also increase IGFBP-5 transcription in C6 glioma cells; however in these cells the cAMP response was mapped to the region immediately distal to the TATA box (Wang et al. 2001). In osteoblasts, prostaglandin $(\mathrm{PG}) \mathrm{E}_{2}$ can increase cAMP, but induction of IGFBP-5 transcription in these cells required the CGAAT/enhancer binding protein $(\mathrm{C} / \mathrm{EBP})$ and $\mathrm{E}$ box recognition sites located within 70 base pairs upstream of the transcription start site (Ji et al. 1999). Other studies have shown that both cortisol and osteogenic protein-1 (OP-1) inhibit IGFBP-5 gene expression through the E box motif (Gabbitas et al. 1996, Yeh \& Lee 2000).

We have previously demonstrated that parathyroid hormone (PTH) induces IGFBP-5 mRNA expression in the osteosarcoma cell line, UMR106-01 cells (Erclik \& Mitchell 2002). The effects of PTH in these cells are initiated by the activation of its G protein-coupled PTH/ PTH related peptide receptor (Bringhurst et al. 1993). Binding of the receptor initiates activation of adenylyl cyclase by $\mathrm{G}_{\mathrm{s}} \alpha$ and phospholipase $\mathrm{C}-\beta$ (PLC- $\beta$ ) by $\mathrm{G}_{\mathrm{q} / 11} \alpha$ (Nissenson \& Arnaud 1979, Mitchell \& Bansal 1997). Our studies showed that PTH activated both cAMP and PLC- $\beta$ in the UMR106-01 cells and that regulation of protein kinase $\mathrm{C}-\delta(\mathrm{PKC}-\delta)$ contributed to the increase in IGFBP-5 mRNA levels (Erclik \& Mitchell 2002). The present study was undertaken to determine the transcriptional mechanisms by which PTH stimulates IGFBP-5 transcription. By utilizing a luciferase reporter construct driven by the $5^{\prime}$ flanking region of the rat IGFBP- 5 gene in UMR 106-01 cells, we identified a 32 base pair PTHresponsive region. Gel mobility shift assays demonstrated that PTH induces increased protein binding to this region. Mutational analysis within this region revealed the involvement of the AP-2 recognition sequence.

\section{Materials and methods}

\section{Cell culture}

UMR106-01 cells (a generous gift from Dr N Partridge, Department of Physiology and Biophysics, UMDNJRobert Wood Johnson Medical School, Piscataway, New Jersey, USA) were grown in 50\% Dulbecco's modified Eagle's medium and 50\% F-12 medium (50:50 DMEM/F-12) containing $1 \mathrm{U} / \mathrm{ml}$ penicillin, $1 \mu \mathrm{g} / \mathrm{ml}$ streptomycin, and $0.25 \mu \mathrm{g} / \mathrm{ml}$ amphotericin $\mathrm{B}$ and supplemented with 5\% fetal calf serum (Invitrogen Technologies, Burlington, ON, Canada).

\section{Northern and slot blot analysis}

UMR106-01 cells were treated for $6 \mathrm{~h}$ with various concentrations of rat $\mathrm{PTH}(1-34)$ (Bachem Bioscience, King of Prussia, Pennsylvania, USA) in 50:50 DMEM/ F-12 media containing $0 \cdot 1 \% \mathrm{BSA}$, and total cellular RNA was isolated with TRIzol reagent (Invitrogen Technologies). For Northern blot analysis, $7 \cdot 5 \mu \mathrm{g}$ total RNA were fractionated on $1.0 \%$ agarose containing $3.7 \%$ formaldehyde. RNA was then transferred onto charged nylon membranes and hybridized to the indicated probes by the method described below. For RNA stability assays, the transcription inhibitor, 5,6dichloro-1-D-ribofuranosylbenzimidazole (DRB) (EMD Bioscience, La Jolla, CA, USA) was used to transcriptionally arrest cells. Having verified by Northern blot that both the IGFBP-5 and glyceraldehyde-3-phosphate dehydrogenase (GAPDH) cDNA probes recognized single transcripts of size 6.0 and $1.3 \mathrm{~kb}$ respectively, we subsequently employed slot blots to assess transcript levels. Samples $(3 \mu \mathrm{g})$ of total RNA were directly blotted onto a nylon membrane by means of a slot blot apparatus and then ultraviolet cross-linked. Blots were prehybridized for $\geq 1 \mathrm{~h}$ in $0.1 \mathrm{M}$ sodium phosphate buffer containing $0 \cdot 1 \%$ BSA, $9 \mathrm{mg} / \mathrm{ml}$ salmon sperm DNA, and $7 \%$ SDS at $65^{\circ} \mathrm{C}$. The 300-bp IGFBP-5 cDNA probe was obtained by digesting IGFBP- 5 cDNA (kindly provided by Dr S Shimasaki, The Whittier Institute for Diabetes and Endocrinology, La Jolla, CA, USA) with HindIII and SacII. The probe was labeled with $\left[\alpha-{ }^{32} \mathrm{P}\right] \mathrm{dCTP}$ by use of the random hexanucleotideprimed method. Hybridizations were carried out in the prehybridization solution overnight at $65^{\circ} \mathrm{C}$, and washes were performed at $65^{\circ} \mathrm{C}$ in $30 \mathrm{mM}$ sodium phosphate buffer containing $0 \cdot 1 \%$ SDS. As loading controls, parallel blots were prepared and hybridized under the same conditions with a probe for $18 \mathrm{~S}$ rRNA for the stability assays and GAPDH for all other assays. Bound RNA was visualized by autoradiography on Kodak X-AR5 film. Signals were quantitated from a phosphorimager using ImageQuant (Amersham).

\section{Preparation of nuclear extracts}

Nuclear extracts were prepared based on the method of Dignam et al. (1983). Briefly, approximately $2 \times 10^{7}$ cells were washed in cold PBS and then scraped in buffer A

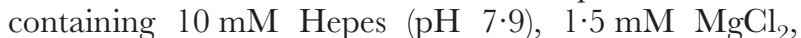
$10 \mathrm{mM} \mathrm{KCl}, 0.5 \mathrm{mM}$ dithiothreitol (DTT) and $2 \mathrm{mM}$ 4-(2-aminoethyl)-benzenesulfonyl-fluoride hydrochloride (AEBSF). Cells were allowed to swell on ice for at least $30 \mathrm{~min}$. Nuclei were pelleted by centrifugation at 1120 $\times \boldsymbol{g}$ for $10 \mathrm{~min}$ and then resuspended in buffer $\mathrm{C}$ containing $40 \mathrm{mM}$ Tris-HCl (pH 7.8), 25\% glycerol, $0.1 \mathrm{M} \mathrm{KCl}, 0.2 \mathrm{mM}$ EDTA, $0.5 \mathrm{mM}$ DTT and $2 \mathrm{mM}$ AEBSF. Nuclei were lysed in buffer $\mathrm{C}$ by sonication on 
Table 1 Summary of oligonucleotides used for luciferase assays and EMSA

Sequence

Common forward primer for deletions and mutants

FP3Xho 5'-AGATCTCGAGCGGCCGCCAGTTG-3'

BP-394 5'-TGTAGGTACCTAGGGTATACACGG-3'

BP-161 5'-AATAGGTACCGTGTCTAGAAGGCC-3'

BP-96 5'-AAATGGTACCCTTGCATGGGTTGGG-3

BP-59 5'-AATAGGTACCCTACAACTGGCTGGC-3'

C/EBP Forward 5'-CCAGTTGTAGCTGGCGTTTGAGCTCCCC-3'

Reverse 5'-GGGGAGCTCAAACGCCAGCTACAACTGG-3'

E-box Forward 5'-GCTGCCAGCCCATGGTAGCTGCAATTTGAGC-3'

Reverse 5'-GCTCAAATTGCAGCTACCATGGGCTGGCAGC-3'

NF-1 Forward 5'-GACGGCCCCAAACTGCCAGCCAGTTGTAGC-3'

Reverse 5'-GCTACAACTGGCTGGCAGTTTGGGGCCGTC-3'

AP-2 Forward 5'-GCTTTTAAATAGACTTTGTCTTTGTGCCAGCC-3'

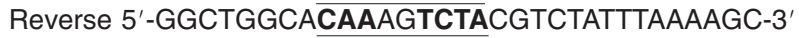

Primers for generation of double stranded oligonucleotides spanning PTH-responsive element

FP939'-ACTGCGGGCTCTGGTCGAG-3

RP869 5'-ATTGCAGCTACAACTGGCT-3'

Underlined regions indicate the recognition sequence for the Indicated factor. Nucleotides in bold are the mutations introduced to eliminate protein binding.

ice and then centrifuged for $30 \mathrm{~min}$ at $25000 \times \boldsymbol{g}$. The clear supernatant was then collected and assayed for protein concentration using the Amido Black method (Schaffner \& Weissmann 1973).

\section{Electrophoretic mobility shift assay (EMSA)}

A double stranded oligonucleotide probe spanning the region between -68 to -20 of the rat IGFBP- 5 proximal promoter was prepared by PCR amplification of the region using the primers 939 and 869 (Table 1).] Purification of the PCR product was followed by end-labeling with $\gamma$-ATP- ${ }^{32} \mathrm{P}$ in a reaction catalyzed by T4 polynucleotide kinase. Nuclear extract $(10 \mu \mathrm{g})$ was incubated at room temperature for $10 \mathrm{~min}$ in binding buffer containing $4 \%$ glycerol, $1 \mathrm{mM} \mathrm{MgCl}_{2}, 0.5 \mathrm{mM}$ EDTA, $0.5 \mathrm{mM}$ DTT, $50 \mathrm{mM} \mathrm{NaCl}, 10 \mathrm{mM}$ Tris- $\mathrm{HCl}$ $(\mathrm{pH} 7 \cdot 5)$ and $50 \mathrm{ng} / \mu \mathrm{g}$ poly(dI:dC). Samples were then incubated for $20 \mathrm{~min}$ at room temperature with $20000-40000$ c.p.m. of probe and then fractionated on a $4 \%$ nondenaturing polyacrylamide gel that was pre-electrophoresed for $20 \mathrm{~min}$ at $250 \mathrm{~V}$ in $0.5 \times$ Tris Borate buffer. Samples were electrophoresed under the same conditions for approximately $45 \mathrm{~min}$. Gels were dried and exposed to X-ray film.

\section{Immunoblotting}

Nuclear extract $(10 \mu \mathrm{g})$ was fractionated on $11 \%$ SDSpolyacrylamide gels and transferred electrophoretically to nitrocellulose membranes overnight at $4{ }^{\circ} \mathrm{C}$. Membranes were blocked for $1 \mathrm{~h}$ in PBS-0.2\% Triton X-100 (PBST) containing 3\% BSA. Membranes were then immunoblotted with monoclonal anti-AP-2 (3E5) developed by Dr Trevor Williams and obtained from the Developmental Studies Hybridoma Bank (developed under the auspices of the NICHD and maintained by The University of Iowa, Department of Biological Sciences, Iowa City, IA, USA). Blots were then probed with horseradish peroxidase-conjugated anti-mouse IgG antiserum, washed, and detected using an enhanced chemiluminescence detection reagent (Amersham Pharmacia, Baie d'Urfe, QG, Canada) on Kodak X-100 ARS film.

\section{Transient transfections and luciferase activity assays}

Cells were grown to $60-70 \%$ confluence in 24-well plates over $48 \mathrm{~h}$ and transfected using lipofectamine reagent (Invitrogen Technologies). The 889 base pairs upstream of the transcription start site and the 114 base pairs of the first exon of the rat IGFBP-5 5' flanking region (kindly provided by Dr J Lee, Department of Biochemistry University of Texas Health Science Centre, Houston, TX, USA) were fused upstream of a promoterless luciferase encoding region in pGL2-Basic (Promega, Madison, WI, USA) (Yeh \& Lee 2000). The luciferase reporter constructs were co-transfected with a beta-galactosidase expression plasmid under the control of a simian-virus 40 promoter (pSV- $\beta$-gal from Promega) 
to correct for transfection efficiency. Twenty-four hours following transfection, cells were treated with PTH for $6 \mathrm{~h}$ and then lysed in $100 \mu \mathrm{l}$ cell lysis buffer (Promega). Luciferase activity was assessed with a commercially available kit (Promega) and was then corrected for beta-galactosidase activity. Luciferase activity increased in a linear fashion with PTH treatment from 3 to $10 \mathrm{~h}$. All the results are presented as relative luciferase activity corrected for beta-galactosidase activity.

\section{Construction of reporter plasmids}

Deletions of the $5^{\prime}$ end of the rat IGFBP- 5 promoter described above waere performed by PCR-based methods. Constructs with $5^{\prime}$ ends at position -889 (full length), $-389,-161,-96$ and -59 relative to the transcription start site were amplified by PGR using $5^{\prime}$ and $3^{\prime}$ primers that contained the linker sequences of KpnI and XhoI respectively and then ligated in pGL2-Basic. Table 1 lists the sequences of the primers used to generate each deletion construct.

Internal mutations of the putative $\mathrm{C} / \mathrm{EBP}, \mathrm{E}-\mathrm{box}$, nuclear factor-1 (NF-1) and AP-2 sites were generated by overlap extension mutagenesis by PCR using the wild-type BP-161 construct as the template. Both sense and anti-sense primers were designed to contain the consensus site for the corresponding factor with specific mutations of residues involved in protein binding. The products of the overlap extension mutagenesis contained the background of the BP-161 construct with targeted mutations to specific consensus sequences. These products were subcloned in the pGL2-Basic vector in the $\mathrm{KpnI}$ and XhoI sites. The sequence for each primer is listed in Table 1. The triple AP-2 reporter construct, kindly provided by Dr Trevor Williams was subcloned in pGL2-Basic vector (Williams \& Tjian 1991).

\section{Statistical analysis}

For luciferase assays, two-way ANOVA was used to compare the means of control and PTH-treated cells in wild-type and deletion/mutant constructs. One-way ANOVA was used to compare the effect of PTH concentration on IGFBP-5 luciferase activity, followed by Bonferroni post-test analysis. All statistical analyses were performed with GraphPad Prism software (GraphPad Software Inc., San Diego, CA, USA).

\section{Results}

\section{PTH induction of IGFBP-5 transcript levels involves} transcriptional mechanisms

PTH induces IGFBP-5 mRNA levels in a concentrationdependent manner in UMR106-01 cells (Fig. 1A). To determine the mechanism of the PTH induction, we first assessed the effect of $\mathrm{PTH}$ on the stability of the IGFBP-5 transcript. The basal levels of IGFBP-5 in UMR 106-01 cells were very low and therefore we first induced the production of mRNA by treating the cells with PTH for $3 \mathrm{~h}$ and assessed the rate of loss of the transcript following addition of DRB. As shown in Fig. 1B, the presence of PTH following transcriptional arrest had no effect on the 17-h half-life of the IGFBP-5 transcript.

To assess the possibility that PTH may increase the rate of transcription of the IGFBP-5 gene we utilized a reporter construct using the first 889 base pairs of the rat IGFBP-5 5' flanking region fused upstream of a promoterless firefly luciferase reporter gene in the pGL2-Basic vector ( -889 BP-5). The reporter construct was transiently transfected along with cDNA encoding $\beta$-galactosidase to assess transfection efficiency. This region of the IGFBP-5 gene has previously been shown to respond to various factors including cAMP, $\mathrm{PGE}_{2}$ and OP-1. Luciferase activity associated with the pGL2 vector alone was extremely low and PTH did not affect its activity (data not shown). Following six hours of PTH treatment there was a concentration-dependent increase in luciferase activity associated with the -889 BP-5 construct (Fig. 2). PTH at $10 \mathrm{nM}$, the concentration at which PTH induced a 10- to 20-fold increase in mRNA levels (Fig.1A), induced a 5- to 10-fold stimulation of luciferase activity (Fig. 2). These studies demonstrated that PTH could indeed increase transcription of the IGFBP-5 gene in UMR106-01 cells and that the response to the hormone was contained within the 889 base pair region of the IGFBP-5 5' flanking region.

\section{Identification of PTH-responsive IGFBP-5 promoter sequences}

In order to identify the regions within the IGFBP-5 5' flanking region that were sensitive to PTH treatment, reporter constructs were generated by the selective deletion of $5^{\prime}$ sequence of the -889 BP-5 construct. As shown in Fig. 3, removal of 495 (BP5-394), 728 (BP5-161), 793 (BP5-96) and 830 (BP5-59) base pairs from the $5^{\prime}$ end of the full length 889 base pair reporter construct had very little effect on basal luciferase activity - the shortest construct, BP5-59, retained approximately $80 \%$ of luciferase activity relative to the full-length construct. PTH induction of reporter activity was similarly not affected by these deletions suggesting that the major PTH responsive region resides within the terminal 59 base pairs of the IGFBP-5 5' flanking region.

As shown in Fig. 4A several regulatory elements exist within the 59 base pair PTH-response region and their significance in mediating the effects of various endogenous factors in multiple cell types has been 


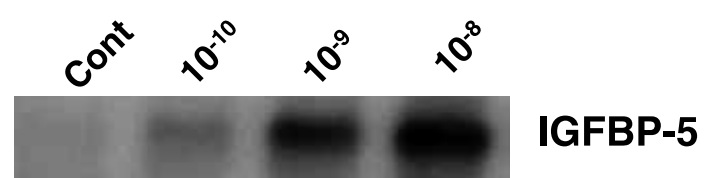

A GAPDH

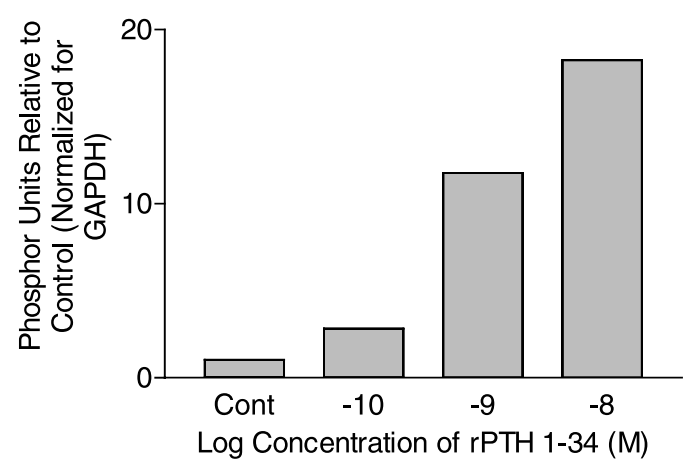

$\mathrm{B}$

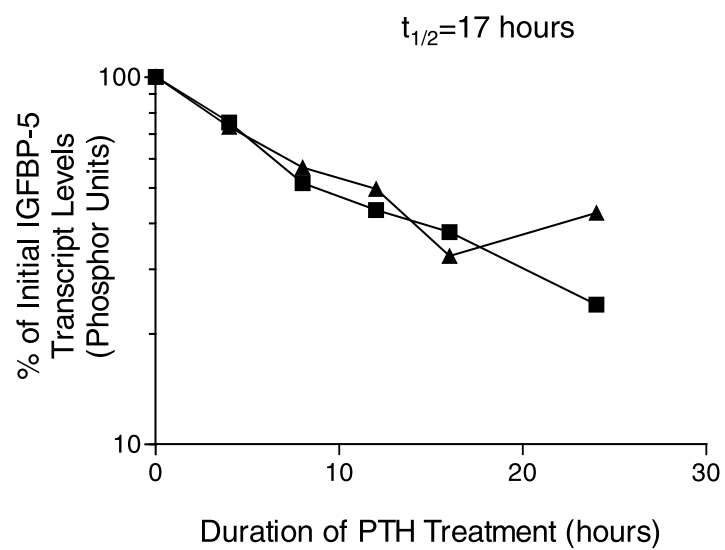

Figure 1 The effect of PTH on IGFBP-5 mRNA stability in UMR106-01 cells. (A) The concentration-dependent induction of IGFBP-5 mRNA by PTH. UMR106-01 cells were treated with the indicated concentrations of PTH for $6 \mathrm{~h}$ and then total RNA was collected. Total RNA was separated by denaturing agarose gel electrophoresis containing 3.7\% formaldehyde. RNA was transferred onto nylon membranes and then hybridized to IGFBP-5 and GAPDH cDNA probes. Values expressed have been corrected for GAPDH. Data are representative of three independent experiments with qualitatively identical results. (B) To assess the effect of PTH on the rate of loss of transcript, cells were treated with $10 \mathrm{nM}$ PTH for $3 \mathrm{~h}$ followed by $75 \mu \mathrm{M}$ DRB. Cells were then treated either with $(\square)$ or without $(\mathbf{\Delta})$ PTH for the indicated times and RNA collected. Total RNA was directly blotted onto nitrocellulose using a slot blot apparatus and hybridized with IGFBP-5 CDNA probe and 18S to control for loading. Bands were quantitated by phosphorimager and the values expressed are corrected for $18 \mathrm{~S}$ and are normalized for IGFBP-5 transcript for control samples (100\%). Data are representative of three independent experiments with qualitatively similar results. Cont, control.

demonstrated. In order to determine whether any of the C/EBP, E-box, NF-1 or AP-2 elements were necessary in mediating the PTH induction of IGFBP-5 promoter activity in UMR106-01 cells, we mutated specific base pairs within each of the recognition sites using the BP-161 construct as the template and assessed whether there was a loss of PTH responsiveness. As shown in Fig. 4B, mutation of three nucleotides within the $\mathrm{G} / \mathrm{EBP}$ recognition sequence had no significant effect on PTH-induced luciferase activity compared with the wild-type BP-161 construct. Likewise, mutations in the E-box and NF-1 sites did not significantly reduce IGFBP-5 basal or PTH-induced promoter activity, and mutation of the E-box slightly increased PTH responsiveness. Mutation of the AP-2 site had no effect on basal promoter activity but PTH-driven luciferase activity was reduced by approximately $50 \%$ in the AP-2 mutant compared with the wild-type, BP-161 construct.

\section{PTH regulation of AP-2 protein levels and activity in UMR106-01 cells}

The AP-2 family of proteins includes several subtypes, $\mathrm{AP}-2 \alpha, \mathrm{AP}-2 \beta$ and $\mathrm{AP}-2 \gamma$ and their expression is

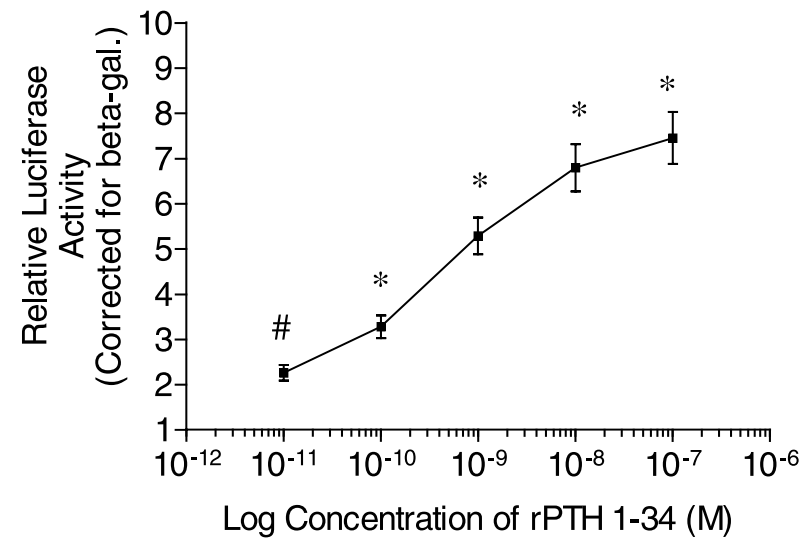

Figure 2 Concentration-dependent induction of IGFBP-5 5 'flanking region reporter activity. The 889 base pairs of the IGFBP-5 5' flanking region were fused upstream of a luciferase reporter gene and then transfected into UMR106-01 cells with a beta-galactosidase expression plasmid. Twenty-four hours following transfection, cells were treated with the indicated concentrations of PTH for $6 \mathrm{~h}$ and then lysed. Luciferase activity and beta-galactosidase activity were then assessed. Values have been corrected for beta-galactosidase (beta-gal.) and PTH stimulation is shown as fold-stimulation over control. Data represent means \pm S.E. of $3-10$ experiments. \# $P<0.01$, ${ }^{\star} P<0.001$, significantly different from unstimulated activity. 


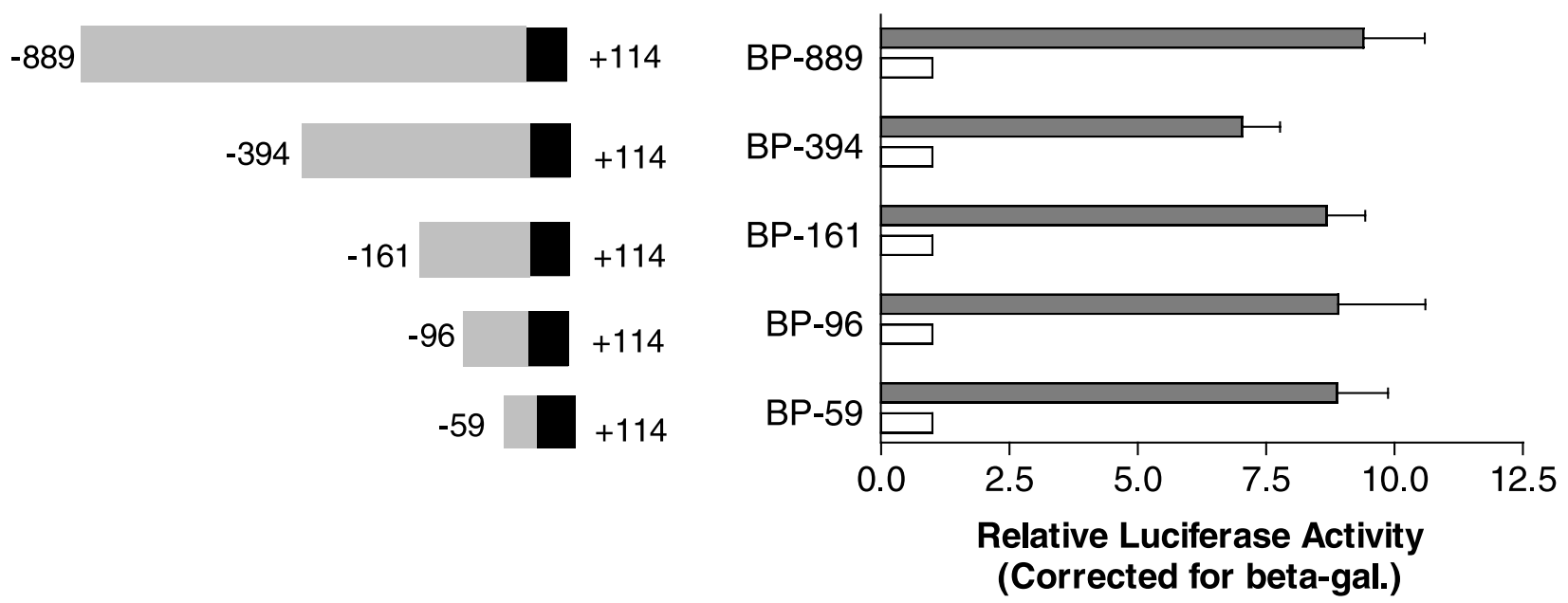

Figure 3 Analysis of luciferase activity of rat IGFBP-5 5' deletion constructs. Luciferase- wild-type and $5^{\prime}$ deletion constructs were transfected and $24 \mathrm{~h}$ later they were treated with $10 \mathrm{nM} \mathrm{rPTH}$ for $6 \mathrm{~h}$ and then lysed. Luciferase activity was corrected for beta-galactosidase activity and PTH induction is expressed as fold stimulation over the activity associated with non-treated cells of the same construct (control). Open bars represent controls (non-treated cells) and solid bars represent PTH-treated cells. Data represent means \pm S.E. of 3-10 experiments. No values were statistically different from wild-type BP-161.

cell-type dependent. The demonstration that the proximal AP-2 site $(-42$ to -33$)$ in the human IGFBP-5 promoter in fibroblasts mediated part of the cAMPinduced increase in IGFBP-5 gene expression, was shown to occur through activation of AP-2 $\alpha$ specifically. The rat, mouse and human IGFBP-5 promoters contain the identical consensus recognition sequence for AP-2, GCCnnnGGC (Fig. 5). In light of the previous findings in fibroblasts, we sought to verify that AP-2 $\alpha$ is expressed in UMR106-01 cells and to determine whether PTH affects its expression. Cells were treated for $3 \mathrm{~h}$ with $10 \mathrm{nM} \mathrm{rPTH}(1-34)$ and nuclear extracts were prepared. UMR106-01 cells express the $43 \mathrm{kDa}$ protein AP- $2 \alpha$ that is at least partially localized to the nucleus (Fig. 6A). PTH had no effect on the level of expression of AP-2 $\alpha$, which is consistent with previous reports suggesting that the protein kinase $\mathrm{A}(\mathrm{PKA})$ and $\mathrm{PKC}$ regulation of $\mathrm{AP}-2$ activity occurs through non-translational mechanisms (Imagawa et al. 1987).

As a means of assessing the PTH effects on AP- $2 \alpha$ activity, we utilized an AP-2 reporter that was constructed by fusing three tandem repeats of the AP-2 consensus recognition sites upstream of a luciferase reporter. PTH induced an approximate $30 \%$ increase in luciferase activity compared with the control vector that did not contain the three AP-2 sites (Fig. 6B).

\section{Nuclear factor binding to the proximal IGFBP-5 element}

To corroborate our findings from the reporter assay that PTH regulates IGFBP-5 transcription through the 70 base pair region upstream of the transcription start site, we performed gel mobility shift assays to assess PTH regulation of nuclear factor binding to this region. Nuclear extracts were prepared from control cells and cells treated with PTH for $1 \mathrm{~h}$ and then incubated with a ${ }^{32}$ P-labeled double stranded oligonucleotide spanning the 70 base pair region. As shown in Fig. 7, PTH increased the binding of nuclear factors to the PTH-responsive region after $1 \mathrm{~h}$ of treatment. Transcription factor binding to this segment of DNA was demonstrated to be specific by competition with a 50 -fold molar excess of cold oligonucleotide. Luciferase assays suggested that the AP-2-like element mediated part of the PTH responsiveness of the 70 base pair region. To determine whether nuclear factor binding to the PTH-responsive region occurred through binding to the AP-2-like element, we generated an AP-2 mutant oligonucleotide. In contrast to the competition achieved with a 50-fold molar excess of cold oligonucleotide, excess cold mutant oligonucleotide bearing mutations in the AP-2 sequence was incapable of competing with the protein binding of the wild-type probe. Gel-shift analysis using the mutant AP-2 oligonucleotide as the probe demonstrated very low levels of transcription factor binding.

\section{Discussion}

PTH stimulates IGFBP-5 mRNA levels in osteoblasts and we have previously demonstrated in UMR106-01 cells that this occurs through activation of both PKA and PKC- $\delta$. In the present report we have demonstrated that this occurs through PTH activation of IGFBP-5 gene transcription. Earlier work by Ji et al. (1999) indicated 


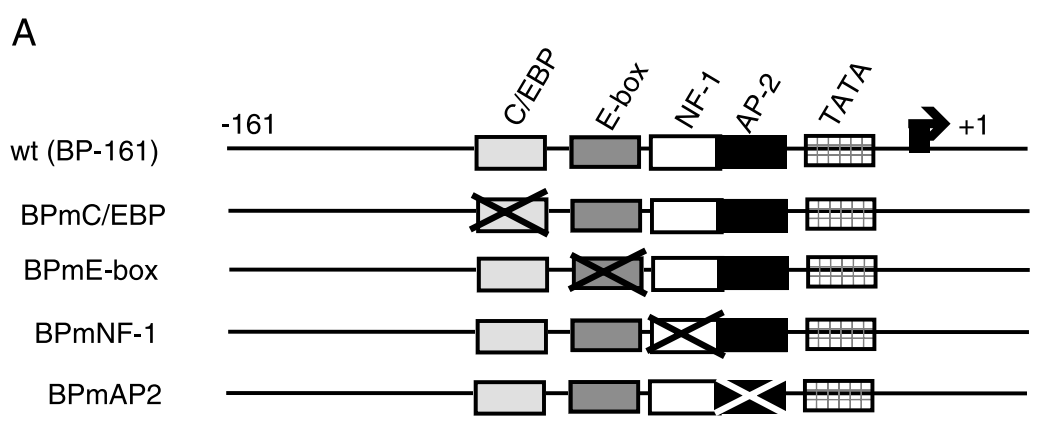

B

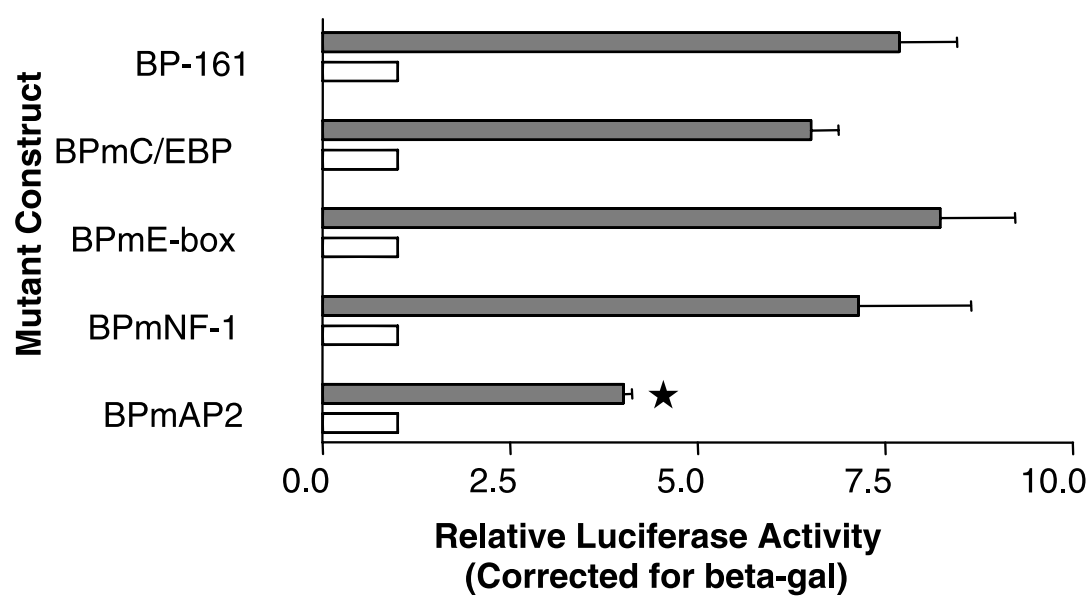

Figure 4 Analysis of luciferase activity of proximal IGFBP-5 promoter elements. (A) Schematic representation of the location of C/EBP, E-box, NF-1 and AP-2 consensus sites relative to the TATA box and transcription start site (designated as +1 ) in the rat IGFBP-5 promoter. C/EBP is located between -58 and -66 , E-box between -50 and $-56, N F-1$ between -29 and -42 and AP-2 between -35 and -43 . A cross in a corresponding box indicates mutations (m). wt, wild-type. (B) Effect of $10 \mathrm{nM}$ PTH on IGFBP-5 promoter mutants. Open bars represent controls (non-treated cells) and solid bars represent PTH-treated cells. Data represent means \pm S.E. of 3-10 experiments. PTH stimulation is expressed as fold stimulation of non-treated cells transfected with the same construct. The star indicates that the value is significantly different from wild-type BP-161 activity $(P<0.05)$.

that the $\mathrm{PGE}_{2}$ induction of IGFBP-5 in primary osteoblasts via increased cAMP occurred by both transcriptional-dependent and -independent mechanisms. We postulated that, due to the very low levels of the IGFBP-5 transcript in UMR106-01 cells, the PTH induction likely occurred through transcriptional mechanisms. Indeed, analysis of the stability of IGFBP-5 mRNA in these cells indicated that PTH had no effect on the half-life of the transcript, suggesting that transcriptional mechanisms were primarily responsible for the 10- to 20-fold induction of IGFBP-5 mRNA levels that can be seen with PTH treatment in these cells.

$$
\begin{aligned}
& \text { Rat- caaat tgcagctac aactggctgg cojgcragggg dcgtctatt aaagcgcct } \\
& \text { Mouse-caat tgcagctac aactggctgg cogccagggg dcgtctattt aaaagcgcct } \\
& \text { Human-caaat tgcagctacaaactggctgg cagccagggg dcggctattt aaagcgcct }
\end{aligned}
$$

Figure 5 Sequence comparison of rat, mouse and human proximal IGFBP-5 promoter region alignment of a portion of the proximal promoter region of IGFBP-5 between species. The sequence includes the CAAT box and the adjoining sequence up to the putative transcription start site for each gene. The consensus AP-2 element for each gene is contained within the box. 


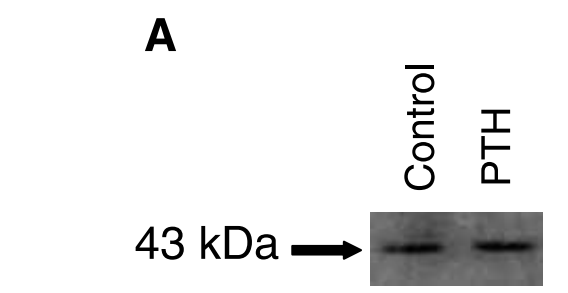

B

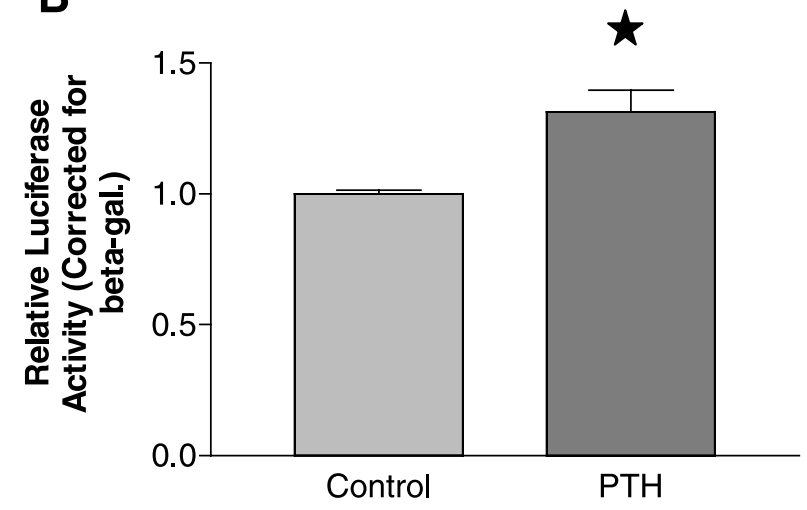

Figure 6 Effect of PTH on AP-2 $\alpha$ expression and transactivation of AP-2 consensus site. (A) UMR106-01 cells were treated with $10 \mathrm{nM}$ PTH for $3 \mathrm{~h}$ and nuclear extracts were prepared. Nuclear extracts $(100 \mu \mathrm{g})$ were fractionated by SDS PAGE and probed with a monoclonal AP- $2 \alpha$ antibody.

(B) UMR106-01 cells were transfected with a luciferase reporter construct containing three tandem repeats of the AP-2 consensus recognition sequence. Induction by PTH was determined by luciferase activity associated with PTH treatment of the three AP-2 constructs over PTH-induced activity associated with vector without the AP-2 repeats. Controls were determined in the same way with non-treated cells and values for both PTH and control are expressed as fold stimulation over control. Data represent means \pm S.E. of 3 experiments. The star indicates that the value is significantly different from control $(P<0.01)$.

We have demonstrated that PTH induces the activity of a luciferase reporter driven by 889 base pairs of the rat IGFBP-5 5' flanking region. Within the 889 base pair region upstream of the transcription start site there were no consensus sites for transcription factors previously shown to be regulated by PTH. Runx2, for example, is a bone-specific factor whose activity is intrinsic to the process of osteoblast differentiation. Runx2 is involved in the control of a number of osteoblastic genes including the PTH induction of matrix-metalloproteinase-13 gene expression (Winchester et al. 2000, Hess et al. 2001). A consensus OSE2 site, the corresponding cis-element for Runx2, was not found in our analysis of the 889 base pair $5^{\prime}$ flanking region of IGFBP-5. Similarly, the consensus binding sequences for additional PTHregulated nuclear factors including AP-1, cAMP responsive element (GREB) and osteogenic factor-1

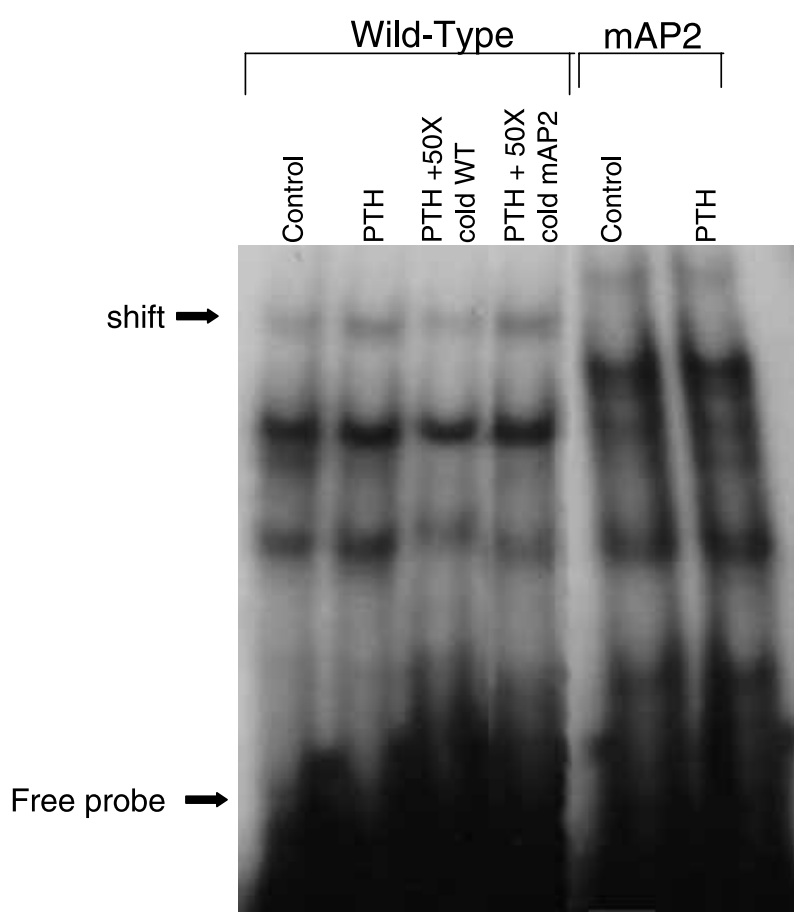

Figure 7 Nuclear factor binding to the PTH-responsive region of the IGFBP-5 promoter. UMR106-01 cells were treated with $10 \mathrm{nM}$ PTH for the indicated times and nuclear extracts were prepared. Nuclear extracts $(10 \mu \mathrm{g})$ were incubated with a double stranded oligonucleotide labeled with ${ }^{32} \mathrm{P}$ spanning the region that contained either the C/EBP, E-box, NF-1 and AP-2 elements $(-68$ to -20$)$ (Wild-Type; WT) or the same region containing a mutated AP-2 site of the rat IGFBP-5 promoter (mAP2). For competition experiments, nuclear extracts were pre-incubated with a 50 -fold molar excess of unlabeled wild-type or mutant oligonucleotides and then labeled probe was added. Results shown in the figure are representative of 3-5 experiments.

(Osfl) were also absent. Using deletion analysis we eliminated a role for the region upstream of the first 161 base pairs of the IGFBP-5 promoter in PTH-stimulated activation. The original analysis of the mouse IGFBP-5 $5^{\prime}$ flanking region by Kou et al. (1995) using DNase I footprinting and gel-mobility shift experiments, identified a transcription factor binding region between base pairs -70 to -34 , a region that is significantly conserved in the human and rat promoters. Consistent with this original report, subsequent investigations have implicated the proximal 70 base pair region of the promoter in the transcriptional regulation of the IGFBP-5 gene by several factors that, like PTH, can increase intracellular cAMP. However, each study has identified different regions responsible for this regulation.

Our studies in UMR106-01 cells reported here have demonstrated the involvement of an AP-2 element in the PTH induction of IGFBP-5 transcriptional activity. Our conclusion is based on the findings that mutation of the 
putative AP-2 consensus sequence within the IGFBP-5 promoter region reduced PTH-stimulated reporter activity by $50 \%$ and eliminated PTH stimulation of protein binding to the IGFBP-5 promoter. PTH was also shown to stimulate the activity of a luciferase construct driven by three tandem repeats of an AP-2 consensus sequence. Our data agree with previous findings in dermal fibroblasts that the AP-2 site is involved in regulation of IGFBP-5 gene transcription (Duan \& Clemmons 1995). This AP-2 site is conserved in the mouse, rat and human IGFBP- 5 promoters. Its phylogenic conservation suggests its significant role in the regulation of IGFBP-5 gene expression.

This is the first report presenting direct evidence for gene regulation by $\mathrm{PTH}$ through an AP-2 element in osteoblasts. This result is of particular interest following two recent investigations aimed at identifying common transcription elements in PTH-regulated genes; both studies identified the AP-2 recognition sequence, suggesting a prominent role for factors that bind to this element in mediating PTH regulation of osteoblast function (Qin et al. 2003, Qiu et al. 2003). We now provide direct evidence for the functional involvement of an AP-2 element in a PTH-regulated gene. The control of eukaryotic gene expression is a process involving the coordinated action of various DNA binding proteins and their association with co-activators and co-repressors.

Our finding that the disruption of the AP-2 sequence does not completely eliminate the PTH response is strongly suggestive of additional factors that may interact with proteins binding to the AP-2 element that are required for maximal induction of IGFBP-5 transcription by PTH. The mutation we introduced to disrupt the AP-2 element partially overlaps with the NF-1 element and subsequently may modify its ability to be bound by nuclear factors. Consistent with the notion that the NF-1 element may be involved in the $\mathrm{PTH}$ regulation of IGFBP-5 transcription, Ji et al. (1999) demonstrated in primary osteoblasts that cooperative nuclear factor binding to the E-box, NF-1 and C/EBP elements regulated IGFBP-5 basal and $\mathrm{PGE}_{2}$-dependent promoter activity. However, in contrast to our findings here that the AP-2 element is a primary mediator of PTH-stimulated IGFBP-5 transcription, Ji et al. found that mutation of the AP-2 element had no effect on $\mathrm{PGE}_{2}$ stimulation in IGFBP-5 reporter assays. Additionally we found no effect of mutations to either the E-box or C/EBP elements in PTH regulation of the IGFBP-5 promoter in the UMR cells. The disparity in our two studies could be the result of differences in the cells used as well as differences in signal transduction by PTH and $\mathrm{PGE}_{2}$. Differences in the regulation of IGFBP-5 activity by the two cell preparations were evident in the differences in basal levels of IGFBP-5 transcription that were high in the primary cell cultures and very low in the UMR cells. The signaling mechanisms of PTH and
$\mathrm{PGE}_{2}$, although similar, are also not the same. PTH receptor activation can stimulate the $\mathrm{PKC}-\delta$ pathway in addition to PKA and we have shown that the activation of PKC- $\delta$ is necessary for maximal induction of IGFBP-5 transcript levels by PTH in the UMR106-01 cells. Both PKA and PKG have been shown to regulate AP-2 and activation of both pathways by PTH may account for the differences observed in transcriptional mechanisms as well as the higher, five- to tenfold, induction of gene expression by PTH compared with the twofold induction observed with $\mathrm{PGE}_{2}$ (Imagawa et al. 1987).

In summary, we have demonstrated that PTH regulated IGFBP-5 gene transcription in UMR106-01 osteoblastic cells through an AP-2 consensus binding site within the proximal gene promoter. These studies support previous work that has identified AP-2 elements as a potentially important mediator of PTH effects on osteoblasts. Our future studies will focus on identification of additional PTH-regulated factors that may act cooperatively with AP-2 in the regulation of IGFBP-5 gene transcription.

\section{Acknowledgements}

This work was funded by a grant from the Canadian Institutes for Health Research. M S Erclik was supported by scholarships from the Canadian Institutes for Health Research, Ontario Graduate Scholarship Program and the Connaught Foundation. The authors declare that there is no conflict of interest that would prejudice the impartiality of this scientific work.

\section{References}

Andress DL 2001 IGF-binding protein-5 stimulates osteoblast activity and bone accretion in ovariectomized mice. American fournal of Physiology, Endocrinology and Metabolism 281 E283-E288.

Andress DL \& Birnbaum RS 1992 Human osteoblast-derived insulin-like growth factor (IGF) binding protein-5 stimulates osteoblast mitogenesis and potentiates IGF action. Fournal of Biological Chemistry 267 22467-22472.

Bautista CM, Mohan S \& Baylink DJ 1990 Insulin-like growth factors I and II are present in the skeletal tissues of ten vertebrates. Metabolism 39 96-100.

Bringhurst FR, Juppner H, Guo J, Urena P, Potts JT Jr, Kronenberg HM, Abou-Samra AB \& Segre GV 1993 Cloned, stably expressed parathyroid hormone (PTH)/PTH-related peptide receptors activate multiple messenger signals and biological responses in LLC-PK1 kidney cells. Endocrinology 132 2090-2098.

Campbell PG \& Andress DL 1997 Insulin-like growth factor (IGF)-binding protein-5-(201-218) region regulates hydroxyapatite and IGF-I binding. American fournal of Physiology 273 E1005-E1013.

Canalis E, McCarthy T \& Centrella M 1988 Isolation of growth factors from adult bovine bone. Calcified Tissue International $\mathbf{4 3}$ 346-351.

Devlin RD, Du Z, Buccilli V, Jorgetti V \& Canalis E 2002 Transgenic mice overexpressing insulin-like growth factor binding 
protein-5 display transiently decreased osteoblastic function and osteopenia. Endocrinology 143 3955-3962.

Dignam JD, Lebovitz RM \& Roeder RG 1983 Accurate transcription initiation by RNA polymerase II in a soluble extract from isolated mammalian nuclei. Nucleic Acids Research $\mathbf{1 1}$ 1475-1489.

Duan C \& Clemmons DR 1995 Transcription factor AP-2 regulates human insulin-like growth factor binding protein-5 gene expression. Fournal of Biological Chemistry 270 24844-24851.

Durant D, Pereira R \& Canalis E 2004a Overexpression of insulin-like growth factor binding protein-5 decreases osteoblastic function in vitro. Bone 35 1256-1262.

Durant D, Pereira R, Stadmeyer L \& Canalis E $2004 b$ Transgenic mice expressing selected insulin-like growth factor-binding protein- 5 fragments do not exhibit enhanced bone formation. Growth Hormone and IGF Research 14 319-327.

Erclik MS \& Mitchell J 2002 The role of protein kinase C-delta in PTH stimulation of IGF-binding protein-5 mRNA in UMR-106-101 cells. American Fournal of Physiology, Endocrinology and Metabolism 282 E534-E541.

Firth SM \& Baxter RC 2002 Cellular actions of the insulin-like growth factor binding proteins. Endocrine Reviews 23 824-854.

Gabbitas B, Pash JM, Delany AM \& Canalis E 1996 Cortisol inhibits the synthesis of insulin-like growth factor-binding protein-5 in bone cell cultures by transcriptional mechanisms. Fournal of Biological Chemistry 271 9033-9038.

Hess J, Porte D, Munz C \& Angel P 2001 AP-1 and Cbfa/runt physically interact and regulate parathyroid hormone-dependent MMP13 expression in osteoblasts through a new osteoblast-specific element 2/AP-1 composite element. Fournal of Biological Chemistry 276 20029-20038.

Imagawa M, Chiu R \& Karin M 1987 Transcription factor AP-2 mediates induction by two different signal-transduction pathways: protein kinase $\mathrm{C}$ and cAMP. Cell 51 251-260.

Ji C, Chen Y, Centrella M \& McCarthy TL 1999 Activation of the insulin-like growth factor-binding protein-5 promoter in osteoblasts by cooperative E box, CCAAT enhancer-binding protein, and nuclear factor-1 deoxyribonucleic acid-binding sequences. Endocrinology $1404564-4572$.

Jones JI \& Clemmons DR 1995 Insulin-like growth factors and their binding proteins: biological actions. Endocrine Reviews 16 3-34.

Kou K, Mittanck D, Fu C \& Rotwein P 1995 Structure and function of the mouse insulin-like growth factor binding protein 5 gene promoter. DNA Cell Biology 14 241-249.

McCarthy TL, Casinghino S, Centrella M \& Canalis E 1994 Complex pattern of insulin-like growth factor binding protein expression in primary rat osteoblast enriched cultures: regulation by prostaglandin $\mathrm{E}_{2}$, growth hormone, and the insulin-like growth factors. Fournal of Cell Physiology 160 163-175.

Mitchell J \& Bansal A 1997 Dexamethasone increases G alpha q-11 expression and hormone-stimulated phospholipase $\mathrm{C}$ activity in UMR-106-101 cells. American Fournal of Physiology 273 E528-E535.

Miyakoshi N, Richman C, Kasukawa Y, Linkhart TA, Baylink DJ \& Mohan S 2001 Evidence that IGF-binding protein-5 functions as a growth factor. Fournal of Clinical Investigation 107 73-81.
Mohan S, Nakao Y, Honda Y, Landale E, Leser U, Dony C, Lang K \& Baylink DJ 1995 Studies on the mechanisms by which insulin-like growth factor (IGF) binding protein-4 (IGFBP-4) and IGFBP-5 modulate IGF actions in bone cells. Fournal of Biological Chemistry $27020424-20431$.

Nissenson RA \& Arnaud CD 1979 Properties of the parathyroid hormone receptor-adenylate cyclase system in chicken renal plasma membranes. Fournal of Biological Chemistry 254 1469-1475.

Qin L, Qiu P, Wang L, Li X, Swarthout JT, Soteropoulos P, Tolias P \& Partridge NC 2003 Gene expression profiles and transcription factors involved in parathyroid hormone signaling in osteoblasts revealed by microarray and bioinformatics. Fournal of Biological Chemistry 278 19723-19731.

Qiu P, Qin L, Sorrentino RP, Greene JR, Wang L \& Partridge NC 2003 Comparative promoter analysis and its application in analysis of PTH-regulated gene expression. Fournal of Molecular Biology 326 1327-1336.

Rajaram S, Baylink DJ \& Mohan S 1997 Insulin-like growth factor-binding proteins in serum and other biological fluids: regulation and functions. Endocrine Reviews 18 801-831.

Richman C, Baylink DJ, Lang K, Dony C \& Mohan S 1999 Recombinant human insulin-like growth factor-binding protein-5 stimulates bone formation parameters in vitro and in vivo. Endocrinology $1404699-4705$.

Schaffner W \& Weissmann C 1973 A rapid, sensitive and specific method for the determination of protein in dilute solution. Annals of Biochemistry 56 502-514.

Wang L, Ma X, Yeh LC \& Adamo ML 2001 Differential regulation of IGF-binding protein gene expression by cAMP in rat C6 glioma cells. Endocrinology 142 3917-3925.

Williams T \& Tjian R 1991 Analysis of the DNA-binding and activation properties of the human transcription factor AP-2. Genes and Development 5 670-682.

Winchester SK, Selvamurugan N, D’Alonzo RC \& Partridge NC 2000 Developmental regulation of collagenase-3 mRNA in normal, differentiating osteoblasts through the activator protein-1 and the runt domain binding sites. Fournal of Biological Chemistry $27523310-23318$.

Yeh LC \& Lee JC 2000 Identification of an osteogenic protein-1 (bone morphogenetic protein-7)-responsive element in the promoter of the rat insulin-like growth factor-binding protein-5 gene. Endocrinology 141 3278-3286.

Yin P, Xu Q \& Duan C 2004 Paradoxical actions of endogenous and exogenous insulin-like growth factor-binding protein-5 revealed by RNA interference analysis. Fournal of Biological Chemistry $27932660-32666$.

Zhao G, Monier-Faugere MC, Langub MC, Geng Z, Nakayama T, Pike JW, Chernausek SD, Rosen CJ, Donahue LR, Malluche $\mathrm{HH}$ et al. 2000 Targeted overexpression of insulin-like growth factor I to osteoblasts of transgenic mice: increased trabecular bone volume without increased osteoblast proliferation. Endocrinology 141 2674-2682.

Received 28 February 2005

Accepted 23 March 2005 